\title{
Stage IVB Hypopharyngeal Carcinoma AJCC v8
}

National Cancer Institute

\section{Source}

National Cancer Institute. Stage IVB Hypopharyngeal Carcinoma A/CC v8. NCI

Thesaurus. Code C133010.

Stage IVB includes: (Any T, N3, M0); (T 4b, Any N, M0). T4b: Very advanced local disease.

Tumor invades prevertebral fascia, encases carotid artery, or involves mediastinal structures. N3: T umor with metastasis in a lymph node larger than $6 \mathrm{~cm}$ in greatest dimension and ENE(-); or metastasis in a single ipsilateral lymph node larger than $3 \mathrm{~cm}$ in greatest dimension and $\mathrm{ENE}(+)$; or metastases in multiple ipsilateral, contralateral, or bilateral lymph nodes any with $\mathrm{ENE}(+)$. M0: No distant metastasis. (AJCC 8th ed.) 